\title{
Corticosteroid insensitivity in severe asthma: impaired nuclear translocation of glucocorticoid receptor in airway smooth muscle cells
}

\author{
Pankaj Bhavsar, Pojui Chang, Charis Michaeloudes, Fan Chung \\ From EAACI International Severe Asthma Forum (ISAF 2012) \\ Gothenburg, Sweden. 11-13 October 2012
}

\section{Background}

Patients with severe asthma are less responsive to the beneficial effects of corticosteroid (CS) therapy. CS mediate their therapeutic effects through activation of the glucocorticoid receptor (GR) and suppression of NF- $\kappa \mathrm{B}$ activity.

\section{Objectives}

We investigated whether i) corticosteroid insensitivity was present in airway smooth muscle cells (ASMC) of patients with severe asthma and ii) there was a defect in the molecular action of the glucocorticoid receptor (GR) in ASMC of patients with severe asthma.

\section{Methods}

ASMC of the healthy (12), non-severe (NSA; 10) and severe asthma (SA; 10) obtained from endobronchial biopsies were pretreated with dexamethasone (Dex) at $10^{-10}-10^{-6} \mathrm{M}$ followed by stimulation with TNF- $\alpha$ and IFN- $\gamma(10 \mathrm{ng} / \mathrm{ml}$ each), alone or in combination $(\mathrm{T}+\mathrm{I})$. CXCL8 and CCL11 release was determined by ELISA, GR and p65 protein was assessed by Western Blot, mRNA by RT-qPCR and p65 recruitment to the CCL11 promoter by ChIP assay.

\section{Results}

CCL11 release was higher in ASMC of non-severe but not severe asthmatics and non-asthmatic controls; CXCL8 release was similar in all groups. In severe asthmatics dex $\left(10^{-6} \mathrm{M}\right)$ caused less suppression of CCL11 ( $42 \%$ vs $14 \%, \mathrm{p}<0.05)$ and CXCL8 $(47.88 \%$ vs $26.7 \%$, $\mathrm{p}<0.05)$ compared to non-severe asthmatics or healthy

Experimental Studies, National Heart \& Lung Institute, Imperial College London SW3, UK controls, respectively. TNFa-induced phospho-p38 mitogen-activated protein kinase was increased in severe asthmatic ASMC compared to non-severe and non-asthmatics while a p38 inhibitor increased the inhibitory effect of dex. GR expressed in severe and non-severe asthma was $49 \%$ of that in the healthy $(\mathrm{p}<0.01)$. Dexamethasone-induced GR nuclear translocation at $2 \mathrm{~h}$, in SA, was $60 \%$ of that in either the healthy or NSA $(\mathrm{p}<0.05)$. TNF- $\alpha$ induced greater p65 mRNA expression in SA whereas baseline and TNF $\alpha$-induced nuclear abundance, and dexamethasone suppression of p65 expression, were similar between groups. While not modulating p65 nuclear translocation, dex attenuated $\mathrm{p} 65$ recruitment to the CCL11 promoter in the healthy and NSA, but this suppressive effect was impaired in SA.

\section{Conclusions}

Airway smooth muscle cells of patients with severe asthma are corticosteroid insensitive; this may be secondary to heightened p38 mitogen-activated protein kinase. Decreased GR expression with impaired nuclear translocation in ASMC, associated with reduced dexamethasone-mediated attenuation of p65 recruitment to gene promoters, may underlie the mechanism of CS insensitivity in severe asthma.

Published: 3 May 2013

\section{doi:10.1186/2045-7022-3-S1-O6}

Cite this article as: Bhavsar et al: Corticosteroid insensitivity in severe asthma: impaired nuclear translocation of glucocorticoid receptor in airway smooth muscle cells. Clinical and Translational Allergy 2013 3(Suppl 1):06. 